\title{
An Analysis of the Internal and External Factors of MOOC Learner Keeping Learning and Abandoning
}

\author{
Jingjing Chen* \\ School of Management and E-business \\ Zhejiang Gongshang University \\ Hangzhou, China
}

\author{
Juan Wu \\ School of Management and E-business \\ Zhejiang Gongshang University \\ Hangzhou, China
}

\begin{abstract}
With the development of MOOC teaching products platform, improving the teaching level of MOOC became a hot issue. In the deep integration of "Internet +", virtual simulation and artificial intelligence, the exploration and application of MOOC has become one of the important ways of teaching reform in universities. This paper firstly conducted a survey on the faceto-face questionnaire of student in MOOC learning platform, then established a learning retention relationship model for MOOC learners, used data and Kano model to analyze the willingness of MOOC learners, and finally put forward suggestions about the optimization of platform design, teaching design considering the needs of scholars and the improvement of individual learning retention ability of scholars for MOOC curriculum design. The innovative point of this paper was to analyze comprehensively the internal and external factors affecting continuing learning of students on MOOC and the factors were under review on relating to the surrounding environment and the changes in students' learning attitude and state.
\end{abstract}

Keywords-MOOC; learning retention; investigation; proposal

\section{INTRODUCTION}

China's MOOC construction has entered a rapid development stage. As of January 15, 2018, according to the official website of the Ministry of Education, the number of MOOCs in China has ranked first in the world. More than 200 MOOCs have been registered on international famous course platforms, more than 460 universities have built more than 3200 MOOC online course platforms, and 55 million college students and social learners have chosen relevant courses through MOOC platform. With the deep integration of modern information technology tools such as "Internet +", virtual simulation, AI, and education and teaching, the exploration and application of MOOC has become one of the important ways of teaching reform in universities. The use of large data, cloud computing, Internet platform to collect data, quantitative analysis of MOOC learning behavior has also been paid more and more attention by scholars. MOOC learning adopters, through online course learning and participation in interaction, leave a large amount of learning behavior data for researchers [1]. Through data mining, network platform supporters and curriculum design developers can achieve continuous improvement of platform service support system and spiral improvement of curriculum quality.

The research on how to improve the quality of MOOC and

Sponsor: Education and Science Planning Project of the Education Department of Zhejiang Province the learning effect of MOOC is a hot issue in the current educational circles. The behavior analysis of MOOC learners based on big data mining has entered the stage of in-depth research, which provides a research environment and foundation for diversified exploration. However, the online data available at present can't show the learner's background. Different characteristics of MOOC learners' adoption, different ages and different professional experiences make learners' needs and characteristics of online learning different. The learners' personality is obvious and their learning behavior is complex. Course instructors generally do not understand the motivation and background of MOOC learners, why learners choose online courses, online data MOOC research is still not deep enough, lack of empirical research and other issues.

This study investigates the form of face-to-face questionnaires issued by students of FANYA MOOC learning platform of Zhejiang University of Business and Technology, and establishes a learning retention relationship model for MOOC learners, which has a positive practical significance for the design improvement and practice of MOOC courses.

The rest of this paper is arranged as follows: In Section 2, we extract the research factors and conduct a questionnaire survey, and theorize the model. In Section 3, we explain the research methods. In Section 4, we provide a detailed case study and discuss further details. Finally, we conclude our research.

\section{RESEARCH REVIEW}

It has been pointed out that the completion rate of MOOC learning is low. Although researchers use MOOC online course learner behavior imprints, including registration rate, number of elections/dropouts, video browsing, uploading and downloading, homework submission, completion of tests, interactive discussion and other data for quantitative analysis, many studies have been done on MOOC learning behavior. However, it is difficult for researchers to obtain personalized information such as MOOC background of learner, learning needs, learning experience and learning objectives [2]. This study investigates the students who have participated in FANYA Web-based courses at Zhejiang University of Industry and Commerce, trying to reveal that students with different backgrounds have different motivations to adopt MOOC. It influences their learning behavior and process, and finds out the personal factors and curriculum factors that affect their willingness to keep learning. 


\section{METHODOLOGY}

This study is based on the KANO model constructed by NORTIAKIKANO in Japan. KANO model defines three types of customer needs: basic, expectation and excitement. These three demands are classified according to performance indicators as basic factors, performance factors and incentives. The basic needs are the needs or functions that customers think should have in the product. These basic needs are the functions that the product should have. Through this theory, we can find out the basic needs of MOOC learners, and then improve the MOOC curriculum design.

Relying on the FANYA Network Learning Center of Zhejiang Gongshang University, the research group received 32 valid questionnaires by sending out questionnaires to the registered course students [3]. With the collected data, it focused on the analysis of the relationship between adoption characteristics and learning retention, and its impact on learning effect. Based on the relevant theories of learning behavior, the sample characteristics are analyzed. According to the survey and analysis of the questionnaire, the paper concludes that the main influencing factors of MOOC dropout behavior are learners' own factors, factors from teachers, teaching content and video factors, and MOOC teaching support platform factors. Through the weight analysis of these four factors, the article points out that the learner's own factors are the primary factors leading to MOOC dropout of learners' behavior. Finally, the article puts forward some suggestions for the problems of the high dropout rate and low completion rate of MOOC. The research in this paper will contribute to the sustainable development of MOOC, so that more learners can benefit from the high-quality MOOC curriculum resources [4].

Through articles, self-designed questionnaires, concurrence, reliability analysis and validity test. A case study and text analysis of interview records, we reveal the ideas of participants and deepen our understanding of the motivation and obstacles of students participating in large-scale open online courses (MOOC). We try to understand why learners choose these courses, especially introductions to chemistry or data analysis and statistical inference. And find out the internal and external factors that affect the curriculum design of learning and learning.

Some scholars have tracked the adoption rate of online course learning in eastern and western regions, and found that the students in western regions are significantly less than those in eastern regions. The main reasons are the differences of network development and hardware supporting [5].

MOOC not only optimizes learning experience, but also alleviates the contradictions in traditional classroom. Zhan Dechen, a professor at Harbin University of Technology, is the director of the course "Introduction to Computer-Computing Thought in University" [3]. In the past four years, he has set up an inter-school curriculum working group with teachers from dozens of schools. In his opinion, "MOOC is an important engine to promote the reform of university education supply side". Traditional large-class teaching can play a teacher's role, but its interaction is weak. Small-class teaching has good interaction effect, but it needs more high- quality teachers. The teaching mode of "large-class teaching and small-class discussion" supported by network classroom has been effectively alleviated. Contradictions in the substantive classroom.

Which students are willing to adopt MOOC learning? Why do they adopt MOOC learning? What factors can motivate them to maintain and complete MOOC learning? To study the background and learning experience of MOOC learning adopters and maintainers, to help MOOC curriculum builders improve the details of curriculum design, to enhance the teaching process effect, and to improve the quality and efficiency of MOOC. This research group relies on the online open course sharing platform of Zhejiang universities. The study focuses on interest of students in MOOC learning, fragmentation learning, flexibility and freedom, and this study focuses on other reasons [6].

\section{CASE STUDY}

\section{A. Research design}

The research group is divided into four groups to carry out the investigation, using semi-structured interview questionnaire form, choosing two financial and business universities in Zhejiang Province, Zhejiang University of Industry and Commerce and Zhejiang University of Finance and Economics, two science and engineering universities, Zhejiang University of Technology and China University of Metrology. The respondents were all students in school. A total of 132 valid questionnaires were collected, including 32 from Zhejiang Gongshang University, 40 from Zhejiang University of Finance and Economics, 32 from Zhejiang SciTech University and 28 from China Jiliang University. The distribution of boys and girls and grades are shown in Fig. 1 and Zhejiang Sci-Tech University 2, respectively [7].

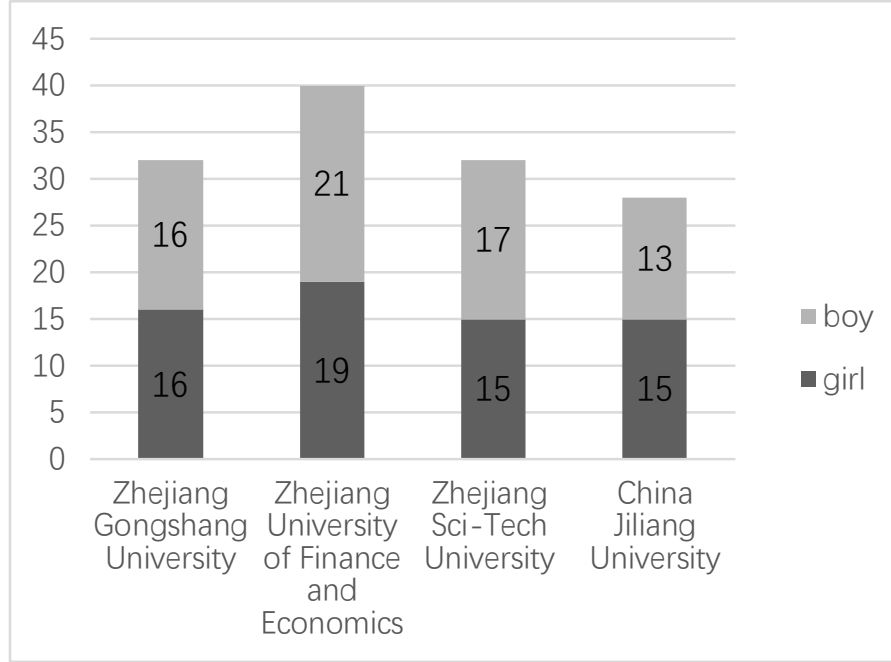

Fig. 1. Distribution of boys and girls 


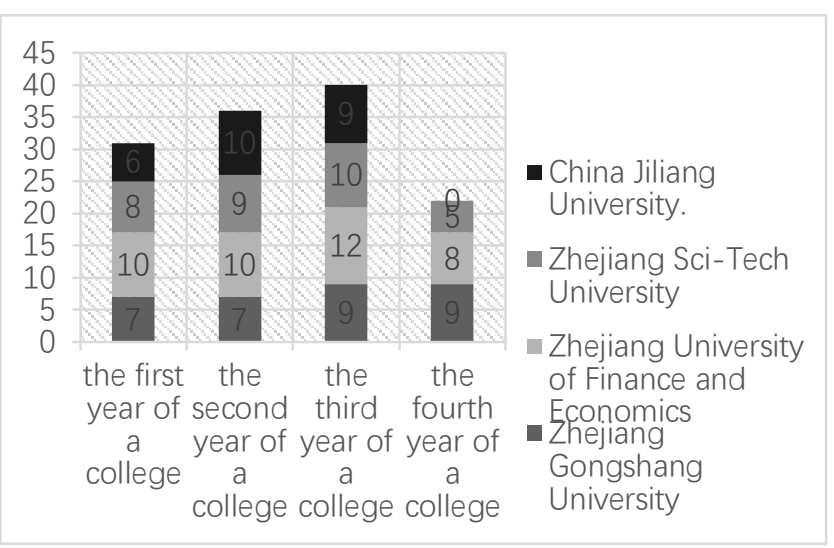

Fig. 2. Distribution of grade

Questionnaire is divided into two parts: the first part is about the basic information of MOOC learners, the second part is about 10 groups of questions, the first-fifth group is related to the learning adoption of MOOC learners, the sixthninth group is related to the continuous learning experience of MOOC learners, and the tenth group is about the evaluation of MOOC satisfaction of learners with the curriculum. The characteristics of MOOC learners in this survey refer to their academic background, gender, grade, and MOOC adoption attitude (active or passive adoption).

\section{B. Analysis of the Impact of MOOC Learning Acceptance Motivation on Online Learning Maintenance}

This study investigates the factors affecting learning retention and interviews with different MOOC learners until the content is saturated.

TABLE I. SURVEY OF INTERNAL AND EXTERNAL CAUSES OF LEARNING MAINTENANCE

\begin{tabular}{|c|c|}
\hline \multicolumn{2}{|c|}{$\begin{array}{c}\text { Investigation on the Internal and External Causes of MOOC } \\
\text { Learning Maintenance }\end{array}$} \\
\hline $\begin{array}{c}\text { For learners who actively adopt } \\
\text { MOOC }\end{array}$ & $\begin{array}{c}\text { For learners who passively adopt } \\
\text { MOOC }\end{array}$ \\
\hline $\begin{array}{l}\text { MOOC learning needs to be self- } \\
\text { demanding, goal-setting and strong } \\
\text { self-control. }\end{array}$ & $\begin{array}{l}\text { Because the course assessment } \\
\text { needs to complete all the learning } \\
\text { contents of MOOC in order to get } \\
\text { high marks and have learning } \\
\text { pressure. }\end{array}$ \\
\hline $\begin{array}{l}\text { Self-study ability is relatively } \\
\text { strong, because it can't be as } \\
\text { convenient as traditional } \\
\text { classroom, prompt questions and } \\
\text { answers. }\end{array}$ & $\begin{array}{l}\text { Asking and answering questions } \\
\text { and answers conveniently in off- } \\
\text { line classes where MOOC courses } \\
\text { are not clear (mixed classes) }\end{array}$ \\
\hline $\begin{array}{l}\text { Learn in groups, find students who } \\
\text { are equally interested in the course, } \\
\text { discuss with each other and urge } \\
\text { each other. }\end{array}$ & $\begin{array}{l}\text { Teachers often urge and remind } \\
\text { everyone of MOOC learning } \\
\text { progress and require participation } \\
\text { and interaction. }\end{array}$ \\
\hline $\begin{array}{l}\text { No matter how much interest and } \\
\text { learning process MOOC course } \\
\text { requires strong willpower. }\end{array}$ & $\begin{array}{l}\text { The content (environment) of } \\
\text { MOOC learning can be easily } \\
\text { completed in a group learning } \\
\text { atmosphere. }\end{array}$ \\
\hline $\begin{array}{l}\text { Learn freely and conveniently. } \\
\text { Teachers can explain clearly. They } \\
\text { can learn what they want. }\end{array}$ & $\begin{array}{l}\text { Teachers can watch videos over } \\
\text { and over again, which is helpful } \\
\text { for mastering difficult points and } \\
\text { high utilization rate of resources. }\end{array}$ \\
\hline
\end{tabular}

TABLE II. SURVEY OF INTERNAL AND EXTERNAL CAUSES OF LEARNING ABANDONMENT

\begin{tabular}{|c|c|}
\hline \multicolumn{2}{|c|}{$\begin{array}{l}\text { Investigation on the Internal and External Causes of MOOC } \\
\text { Learning Abandonment }\end{array}$} \\
\hline $\begin{array}{c}\text { For learners who actively adopt } \\
\text { MOOC }\end{array}$ & $\begin{array}{c}\text { For learners who passively adopt } \\
\text { MOOC }\end{array}$ \\
\hline $\begin{array}{l}\text { I just want to learn what I want, } \\
\text { and I don't want to complete all my } \\
\text { studies, so I don't study completely. }\end{array}$ & $\begin{array}{l}\text { Because of the online learning } \\
\text { part, the proportion of assessment } \\
\text { is relatively small, it does not } \\
\text { affect the passing of the course } \\
\text { (increase the proportion of } \\
\text { assessment of online learning } \\
\text { part). }\end{array}$ \\
\hline $\begin{array}{l}\text { No assessment pressure, } \\
\text { intermittent learning time, too long } \\
\text { duration, so give up }\end{array}$ & $\begin{array}{l}\text { MOOC learning is prone to fatigue } \\
\text { and the inability to concentrate on } \\
\text { a computer screen for a long time. }\end{array}$ \\
\hline $\begin{array}{l}\text { MOOC learning needs to have } \\
\text { strong control and self-reliance, } \\
\text { and feels that there are difficulties } \\
\text { in this respect. }\end{array}$ & $\begin{array}{l}\text { Video design is not dynamic } \\
\text { enough, the course teacher either } \\
\text { stands or sits, and there is no } \\
\text { classroom interaction. }\end{array}$ \\
\hline $\begin{array}{l}\text { Must have strong self-study ability, } \\
\text { because the interaction with } \\
\text { teachers is not as instant as in the } \\
\text { traditional classroom, sometimes } \\
\text { can't continue to learn without } \\
\text { understanding. }\end{array}$ & $\begin{array}{l}\text { In MOOC, the pronunciation and } \\
\text { intonation of the course teachers } \\
\text { are more fixed, less changeable } \\
\text { and dull. }\end{array}$ \\
\hline $\begin{array}{l}\text { Although there are interactive areas } \\
\text { or discussion areas, it takes a long } \\
\text { time to express questions in words, } \\
\text { sometimes inaccurately, without an } \\
\text { effective or targeted answer, so it } \\
\text { gives up (whether voice interaction } \\
\text { or live interaction can be adopted). }\end{array}$ & The course content is rather dull. \\
\hline $\begin{array}{l}\text { MOOC learning requires a long } \\
\text { period of unsupervised attention, } \\
\text { and keep up with the progress of } \\
\text { teachers, more difficult (hope to be } \\
\text { encouraged and inspired by } \\
\text { teachers) }\end{array}$ & $\begin{array}{l}\text { MOOC assessment settings are } \\
\text { relatively simple, no challenge, } \\
\text { can't mobilize the enthusiasm of } \\
\text { learning (hope to be encouraged } \\
\text { and inspired by teachers). }\end{array}$ \\
\hline $\begin{array}{l}\text { MOOC learning often encounters } \\
\text { difficulties, requires a certain } \\
\text { degree of self-confidence, to adhere } \\
\text { to the end, not easy to achieve. }\end{array}$ & Individuals are lazy. \\
\hline $\begin{array}{l}\text { Teaching videos are monotonous, } \\
\text { sometimes dull, and can't be } \\
\text { persevered. }\end{array}$ & $\begin{array}{l}\text { Learning environment without } \\
\text { classroom constraints and lack of } \\
\text { self-control. }\end{array}$ \\
\hline $\begin{array}{l}\text { The absence of group learning } \\
\text { atmosphere and loneliness reduces } \\
\text { the willpower required to maintain } \\
\text { learning. }\end{array}$ & $\begin{array}{l}\text { Self-taught ability is poor, can’t } \\
\text { keep up with the teacher's } \\
\text { explanation, also can’t ask } \\
\text { questions. }\end{array}$ \\
\hline
\end{tabular}

Learning abandonment here refers to those who have participated in some part of the course or some part of the course, but have not completed all the learning and assessment content prescribed by the course [8].

The survey shows that $88 \%$ of the students who actively adopt MOOC study are junior and senior students. The questionnaire shows that senior students are more willing to adopt MOOC study actively. The main purpose of course selection is to improve their competitiveness and social employment competence. The purpose is to improve their own quality and professional ability or develop interest. They pay more attention to themselves. Whether they want to learn, or whether they are interested in learning, $82 \%$ of the students do not care about getting credit or passing the exam, but the need 
for self-satisfaction, which is one of the reasons why the completion rate of MOOC learners is less than $18 \%$.

The questionnaire consists of 10 groups of questions and four groups of online learning questionnaires using Zaharias and Poylymenakou (2009). The evaluation includes curriculum content, curriculum video design, curriculum navigation, curriculum interaction and learning motivation. $\mathrm{Li}$ Shuang et al. (2016) explored the theory and practice of learning behavior analysis and measurement based on learning management system from the perspective of learning behavior input. Through the teaching strategies including the length of time, the pause of teaching gap, the questions in the teaching process and the design of difficult lectures, the influencing factors of Fig. 3 are analyzed.

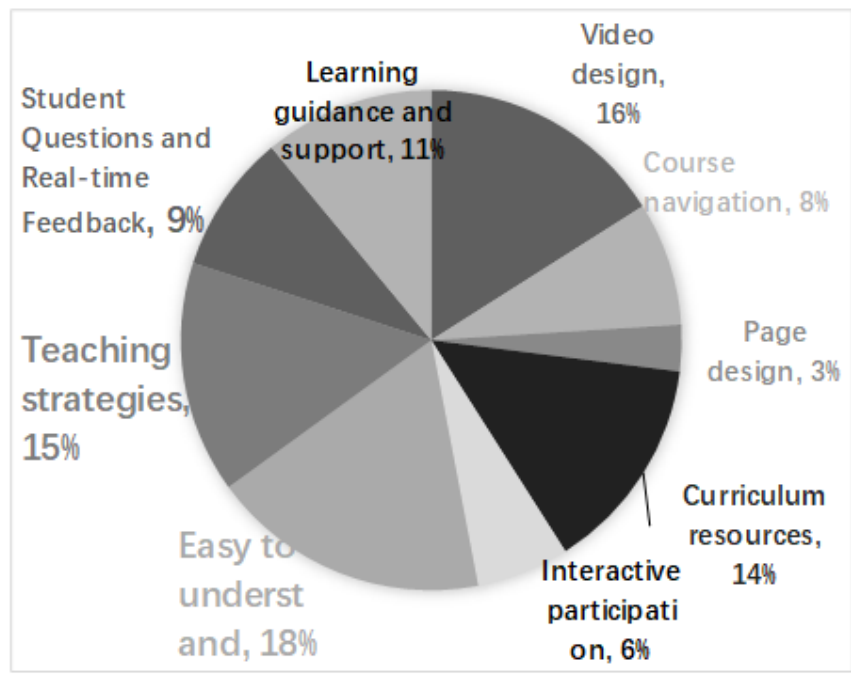

Fig. 3. Analysis of the influencing factors of user learning maintenance

\section{SUMMARY}

By analyzing the internal and external factors of MOOC willingness of learners to learn, and combining with KANO model, we can fully understand the needs of students, including the optimization of curriculum design, the improvement of content understandability, the improvement of teaching strategies and the guidance and support of teachers' curriculum.
Through the research, we put forward some suggestions about the optimization of MOOC platform: the optimization of platform design, teaching design considering the needs of scholars and the improvement of individual learning retention ability of scholars. We conclude that MOOC optimization process is divided into three parts. The first part is platform design optimization and teaching design. The platform design includes curriculum navigation, page design and curriculum resources design. The teaching design includes interactive participation, content understandability, teaching strategies, problem feedback, learner guidance and support and video design. The second part is the learning adoption of MOOC, which includes the adoption of MOOC opinions of designers on the first part. The third part is learning retention of MOOC. The curriculum factors include the relevance of learning content and objectives and curriculum satisfaction. The other is the factors of students, including attention, learning ability and self-confidence.

\section{REFERENCES}

[1] Yao Dandan, Wu Yanni, Xu Zhongfeng, Duan Chen, Mei Hong, Zhang Junbin. The promotion of MOOC on regional educational equity from the perspective of knowledge gap [J]. Chinese medical education technology, 2016, pp.632-635.

[2] Guo Xinyue. MOOC Learning Behavior Analysis within the Framework of Multivariate Analysis [J]. Open Learning Research, 2017.(In Chinese)

[3] Zhang Zhixin, Chen Bo, Zhu Yonghai, et al. [J]. Current situation and problem analysis of Chinese Mu-curricula research. [Modern Educational Technology, 2017.(In Chinese)

[4] Yang Hongyun, Hu Lili, MOOC platform, user completion rate, influencing factors and countermeasures, based on the research of relevant documents at home and abroad, [J]. China education informatization, 2017. (In Chinese)

[5] HOWARTH J P, D'ALESSANDRO S, JOHNSON L, et al. Learner motivation for MOOC registration and the role of MOOCs as a university' taster'[J]. International Journal of Lifelong Education, 2016, pp.74-85.

[6] Study on the influencing factors of dropout behavior of Xu Zhenguo, Zhang Guanwen, Shilin, et al. MOOC learners [J]. Modern Educational Technology, 2017.(In Chinese)

[7] Luo Shuping, Xu Guifang. Application of BIM technology in architectural design and construction [J].Value Engineering, 2018,37(03) 176-177. (In Chinese)

[8] Qudi. Cold Reflections on MOOC Hot - International Reflections on the Six Major Issues of MOOCs Teaching [J]. Distance Education Research, 2014, pp.39-47.(In Chinese) 